Bulz. Pharm. Sci., Assiut University

Vol. 7 part 2, pp. $430-443$

\title{
WITHANOLIDES OF WITHANIA SOMNIFERA L。 DUNAL GROWING WILD IN EGYPT
}

\author{
M.M.EI-Olemy ${ }^{*} \quad \& \quad H . A . K_{\text {Kadry }}^{* *}$ \\ * Department of Pharmacognosy, Faculty of pharmacy, Tanta \\ University, Tanta, Egypt \\ * Department of Pharmacognosy, Faculty of Fharmacy, Al-Azhar \\ University, Cairo, Egypt
}

\begin{abstract}
Three Withanolides (Substances $A, B$, and $C$ ) were isolated from the alcoholic extract of the Egyptian Withania somnifera wild plants. Substance $A$ and substance $C$ were identified by IR, NMR and Mass spectral data. Substance $A$ appears to be a configurational isomer of Withanolide $E$ and substance $C$ is 4-hydroxyderivative of substance $A$. Substance $A$ is identified as $24,27,20-t$ rihydroxy-5B,6B-epoxy-1-oxo-witha-2, 24dienolide (I) and substance $C$ as 4, 24, 27, 20-tetrahydroxy-5B, 6B-epoxy-1-oxo-witha-2, 24-dienolide (II).

This is the first report of isolation and characterisation of substance $C$ from Withania somnifera or the genus Withania. Substance $B$ would be the subject of a further report.
\end{abstract}

\section{INTRODUCTION}

Withania somnifera L. (Dun) is a solanaceous plant, growing wild in Egypt ${ }^{1}$, in the Nile Valley and Delta. The plant is used in Indian and African folk medicine against fever, as a sedative and hypnotic to induce sleep and as antiseptic ${ }^{2,3}$. 
Withanolides of Withania somnifera L. Dunal growing in Egypt.

Literature survey, showed that the roots of the plant yiel-

ded a large number of alkaloids ${ }^{3-10}$, while the leaves gave.a large number of steroidal lactones, termed collectively withanolides 11-24. Such compounds have been shown to possess antitu$\operatorname{mor}^{17,18}$ and antimicrobial activities 25 . Among these compounds, withaferin A, the first compound of this class to be isolated, caused significant retardation of growth of Ehrlich ascites carcinoma, sarcoma and mammary adenocarcinoma ${ }^{18}$.

It was reported that specimen of W.somnifera from various areas yielded different withanolides and that 3 chemotypes grow wild in Israel ${ }^{18}$. These chemotypes differ in the substitution pattern of the steroidal lactones ${ }^{18}$ A fourth chemotype (Indian I) has been shown to occur in North Western India 20.

Since 1965, about fifty withanolides have been isolated from different chemotypes of Withania somnifera ${ }^{11-24}$, as well as several related species of the family Solanaceae e.g. Acnistus ${ }^{26-27}$, Physalis $^{28}$. Datura ${ }^{29}$ and Dunalia species ${ }^{30}$. In Addition, Withanolides have also been shown in the roots of Withania coagulans 31 and were also isolated from the roots of Indian variety of Withania somnifera: 32

Investigation of the leaves of the Egyptian plant has yielded four crystalline compounds 25 , that are still not identified. The authors gave M.P., I.R. and preliminary empirical formulae for their isolated compounds.

In view of the reported antitumor property and antibacterial activity of he somnifera as well as the chemical variability of the specimens from different oological habitats and the specimens 


$$
\text { M.M.EZ-OZemy \& H.A.Kadry }
$$

belonging to different chemotypes, we have undertaken the present investigation of the wild Egyptian plant to isolate and identify its contained withanolides, to determine its relationship to the 4 chemotypes already known, with the hope to identify any hitherto unknown components and if any, to examine their biological activity.

\section{EXPERIMENTAL}

\section{Plant Material:}

The material used in this investigation was the overground parts of Withania somnifera L. (Dunal), collected from the barks of the Nile, Kanater, Cairo, Egypt. Identity of the plant was confirmed by late Prof.Dr. Vivi Tackholm.

Authentic Reference Material

Witheferin $A$, withanolides $D$ and $E$ and Dihydrowithaferin $A^{*}$ Preparation of Ether Extract of W. Somnifera L((Dun):

The dried powdered herb of $W$. somnifera $(650 \mathrm{~g})$ was defatted by percolating with petroleum ether $\left(60-80^{\circ} \mathrm{C}\right)$. The defatted powder was exhaustively extracted by percolation with etha-. nol. $95 \%$. The alcoholic extract was concentrated under reduced pressure to yield $60 \mathrm{~g}$ of a greenish-brown residue: $30 \mathrm{~g}$ of this residue were dissolved in $100 \mathrm{ml}$ of ethanol $95 \%$, diluted with $100 \mathrm{ml}$ of distilled water and partitioned with $5 \times 200 \mathrm{ml}$ of ether. The ether extracts were combined, washed with distilled water, dried with anhydrous sodium sulphate and evaported in vacuum to leave $5 \mathrm{~g}$ of a greenish-brown soft residue.

* Withaferin $A$ and Withanolides $D$ and $E$ were kindly provided by Dr. Lavie, Dept. of Chemistry, Weizmann Institut, Rehovoth, Israel. Withaferin A and Dihydrowithaferin A were also provided by Dr.J. Rosazza, College of Pharmacy, Iowa State University., Iowa City, Iowa, U.S.A. 
Withanolides of Withania somnifera L. Dunal growing in Egypt

\section{Chromatographic Examination of the Ether Extract}

The ether extract of $W$. somnifera was examined by tlc using silica gel $G$ plates. Several solvent systems were tried including: chloroform-absolute ethyl alcohol (76:4), chloroform-ethanol $95 \%(95: 5)$ and ethyl acetate-benzene $(7: 1)^{*}$, p - anisaldehyde/perchloric acid reagent ${ }^{* *}$ was used as spraying reagent. The plates were activated by heating at $120^{\circ} \mathrm{C}$ for 5 minutes; $12-13$ spots appear, the majority of which were coloured blue to greyish-blue to violet.

Column Chromatographic Fractionation of the Ether Extract:

The ether extract of $\frac{\mathrm{W} \text {. somnifera }}{*^{*}}(\mathrm{~g})$ was chromatographed over $100 \mathrm{~g}$ silica gel $\mathrm{G}^{* * *}$ (Merck, Darmstadt, Germany) by gradient elution with mixtures of benzene-ethyl acetate( $7: 3)$, $(5: 5),(3: 7)$, ethyl acetate and ethyl acetate-ethanol $95 \%$ (95:0.5). Thirty fractions (200 $\mathrm{ml} \mathrm{each}$ ) were collected and the pattern of chromatographic separation was followed by tlc examining each fraction and the similar fractions were combined.

Isolation of Sulstance A:

The residue obtained after distilling off the benzeneethyl acetate fractions $(5: 5 \& 3: 7)$ was further purified by chromatography over silica gel $G{ }^{*}$ column. The residue $(0.6 \mathrm{~g})$ was adsorbed on $I$ of silica gel $G$ and the mixture was packed

* Proved to be the most suitable

* $0.5 \mathrm{ml}$ p-anisaldehyde, $50 \mathrm{ml} 60 \%$ perchloric acid, $10 \mathrm{ml}$ acetone and $40 \mathrm{ml}$ distilled water.

* To simulate conditions available in tlc. 
on the top of a column of $15 \mathrm{~g}$ of silica gel-G prepacked in a glass column ( $1 \mathrm{~cm} \varnothing)$ by the wet technique using benzene. Fractionation was carried out by gradient elution with benzene, mixtures of benzene-ethyl acetate in the proportions $9: 1,8: 2$, $7: 3,6: 4,4: 6$ and $2: 8$. Thirty four fractions ( $5 \mathrm{mI}$ each) were collected. Fractions 18 to 23 eluted with benzene-ethyl acetate $(6: 4 \& 4: 6)$ were evaporated under reduced pressure to yield a colourless residue $(40 \mathrm{mg})$. Trials of crystallisation of this residue gave a crystalline product, m.p. $177.5^{\circ} \mathrm{C}$ (decomp.). Thin-layer chromatographic examination of this product using the solvent systems benzene-ethyl acetate ( $I: 7)$ and chloroform-ethanol ( $9: 1$ ) revealed the presence of one spot identical with that of authentic withanolide $E$ and of the $R_{f}$ values 0.38 and 0.5 in the 2 systems respectively.

Isolation of Substance B:

The pale brown residue obtained after distilling off the ethyl acetate fraction of the column chromatographic fractionation of the ether extract, was washed with little benzene till the residue was nearly colourlesss. Trials of crystallisation of this residue yielded a colourless residue ( $15 \mathrm{mg}$ ). Examination of this residue by tlc(using silica gel G plates), the solvent systems benzene-ethyl acetate ( $1: 7)$, ch Ioroformethanol ( $9: 1$ ) and p-anisaldehyde perchloric acid as spraying reagent, revealed the presence of one spot of the $R_{f}$ values 0.25 and 0.48 in the 2 systems respectively. The compound was only obtained in trace amount. This would be chracterized in a further report.

\section{Isolation of Substance C:}

The ethyl acetate-ethanol(9.5:0.5) fractions obtained from the column chromatographic fractionation of the ether 
Withanolides of Withania somnifera L. Dunal growing in Egypt

extract, were collected and evaporated to dryness under reduced pressure. The pale brown residue $(2 \mathrm{~g})$ was dissolved in hot ethanol, filtered and the filtrate was left to stand overnight. A crystalline substance was obtained, further recrystallised from hot ethanol to yield colourless needles, m.p. $277.5^{\circ} \mathrm{C}$. Thin layer chromatographic examination of this crystalline compound using silica gel G plates, the solvent systems benzene-ethyl acetate ( $1: 7)$, chloroform-ethanol (9:I), revealed the presence of one spot of the $R_{f}$ values 0.07 and 0.14 in the 2 systems respectively.

Characterization of the Substance A \& C

Substance A:

M.P. $177.5^{\circ} \mathrm{C}$ (with decomposition): IR (KBr) 3400, 2930, $2920,2865,1690$ (broad), 1380, NMR (CD $O D)$ ppm $(\delta): 1.1(8,3 \mathrm{H}$, $\left.18-\mathrm{CH}_{3}\right), 1.25\left(\mathrm{~s}, 3 \mathrm{H}, 19-\mathrm{CH}_{3}\right), 1.4\left(\mathrm{~s}, 2 \mathrm{I}-\mathrm{CH}_{3}\right), 1.85(\mathrm{~s}, 3 \mathrm{H}, 27-$ $\left.3 \mathrm{H}, 27-\mathrm{CH}_{3}\right), 1.95\left(\mathrm{~s}, 3 \mathrm{H}, 28-\mathrm{CH}_{3}\right), 3.22(\mathrm{t}, 1 \mathrm{H}, 6-\mathrm{H}), 5.9(\mathrm{~d}, 1 \mathrm{H}$, $2-H)$ and $6.9(1 \mathrm{H}, 3-\mathrm{H})$, Mass Spectrum $(\mathrm{m} / \mathrm{e}): 450\left(\mathrm{M}^{+}-2 \times 18\right)$. Thus molecular formula $=\mathrm{C}_{28} \mathrm{H}_{38} \mathrm{O}_{7}, 432\left(\mathrm{M}^{+}-3 \times 18\right), 344,326,299$, $255,237,209,207,175,169,152,135,125$ (100\%, base peak), $109,91,81,79,77,71,69,67$. This substance gave the same $R_{f}$ as authentic withanolide $E$ and both gave superimposable IR spectra; both gave identical fragmentation pattern in the Mass spectrum.

\section{Substance C:}

Major withanolide of the Egyptian plant, mp $277.5^{\circ} \mathrm{IR}(\mathrm{KBr})$ $3450,2960,2880,1675$ (broad), 1450, 1420, 1380, 1330,1290, $1260,1220,1150,1100,1080,1020,960,870,810$ and $770 \mathrm{~cm}^{-1}$; $\operatorname{NMR}\left(\mathrm{CD}_{3} \mathrm{OD}\right) \operatorname{ppm}(\boldsymbol{\delta}): 1.1\left(\mathrm{~s}, 3 \mathrm{H}, 18-\mathrm{CH}_{3}\right), 1.3\left(\mathrm{~s}, 3 \mathrm{H}, 19-\mathrm{CH}_{3}\right)$, $1.4\left(\mathrm{~s}, 3 \mathrm{H}, 21-\mathrm{CH}_{3}\right), 1.85\left(\mathrm{~s}, 3 \mathrm{H}, 27-\mathrm{CH}_{3}\right), 1.95\left(\mathrm{~s}, 3 \mathrm{H}, 28-\mathrm{CH}_{3}\right)$ $3.2(t, 1 H, 6-H), 3.6(d, 1 H, 4-H), 4.6(\mathrm{~m}, 1 \mathrm{H}, 22-\mathrm{H}), 5.8(\mathrm{~d}, 1 \mathrm{H}$ 
$2-\mathrm{H}, 6.7(\mathrm{~m}, 1 \mathrm{H}, 3-\mathrm{H})$; mass spectrum $(\mathrm{m} / \mathrm{e}): 466,\left(\mathrm{M}^{+}-2 \times 18\right)$. Thus Molecelar formula $=\mathrm{C}_{28} \mathrm{H}_{38}{ }^{\mathrm{O}}, 448\left(\mathrm{M}^{+}-3 \times 18\right), 430\left(\mathrm{M}^{+}-\right.$ $4 \times 18) .361,343,317,299,281,244,238,213,209,207$, $185,170,152,125,(100 \%$, base peak), 109, 97, 79,67.

\section{DISCUSSION}

Three substances were isolated from Egyptian Withania somnifera L. (Dural), substance A,B and C. Substance A was the least polar of the three compounds with $R_{f}$ values 0.38 and 0.5 in the solvent systems benzene-ethyl acetat $(1: 7)$ and chloroform-ethanol $(9: 1)$ respectively. It corresponded in every respect with suthentic withanolide E, with superimposable I.R. and identical mass spectral fragmentation pattern; $M^{+}-2 \times 18$ for both was at $\mathrm{m} / \mathrm{e} 450$. Moreover, NMR chemical shift data for the methyl group protons at $\mathrm{C} 18,19,21,27$ and 28 were identical in every respect with that of withanolide $E$. Comparing the NMR data obtained with those reported in the literature $20,22,28$, confirms the substitution pattern of 14, 17, 20-trihydroxy type. 
Withanolides of Withania somnifera L. Dunal growing in Egypt

The chemical shift values of $\mathrm{C}_{27}$ and 28 methyl groups confirm $\Sigma^{4}$ double bond. However, the m.p. of the compound was different from that reported for withanolide E (m.p. 167$\left.168^{\circ} \mathrm{C}\right)^{21}$. The 5,6-epoxide is confirmed from chemical shift of the $6-\mathrm{H}$ giving a triplet at $3.22 \mathrm{ppm}$. Thus the structure of substance $A$ (I) could be a configurational isomer of withanolide E. The aboslute configuration of the side chain at $\mathrm{C}_{17}$ remains to be determined.

Substance $C$ was obtained as the major withanolide of the Egyptian plant. It behaved as the most polar withanolide with $R_{f}$ values 0.07 and 0.14 in the solvent systems benzene-ethyl acetate $(1: 7)$ and chloroform-ethanol (9:1) respectively. Mass spectrum gave $\mathrm{M}^{+}-2 \times 18$ at 466 , indicating the possibility of a hydroxy derivative of substance $A$. NMR spectral data confirmed such assumption. The chemical shift values of the methyl groups at $18,19,21,27$ and 28 were identical to those of withanolide $\mathrm{E}$ and substance $\mathrm{A}$. Moreover, $\mathrm{C}_{22^{-\mathrm{H}}}$ appeared as multiplet at 4.6 , indicating similar hydroxylation pattern to these two compounds at $\mathrm{C}_{17}$ and $\mathrm{C}_{20} 20,22$. The epoxide was also confirmed by chemical shift of $\mathrm{C}_{6}-\mathrm{H}$. The chemical shifts of $27-\mathrm{CH}_{3}$ and $28-\mathrm{CH}_{3}$ protons confirm the presence of a $\Delta^{24}$ double bond. The only difference in NMR spectra of substances $A$ \& $C$ was the appearance of a doublet at $3.6 \mathrm{ppm}$ corresponding to one proton indicating a $4-O H$ group. Thus substance $C$ (II) is 4-h ydroxy-8ubstance A. 


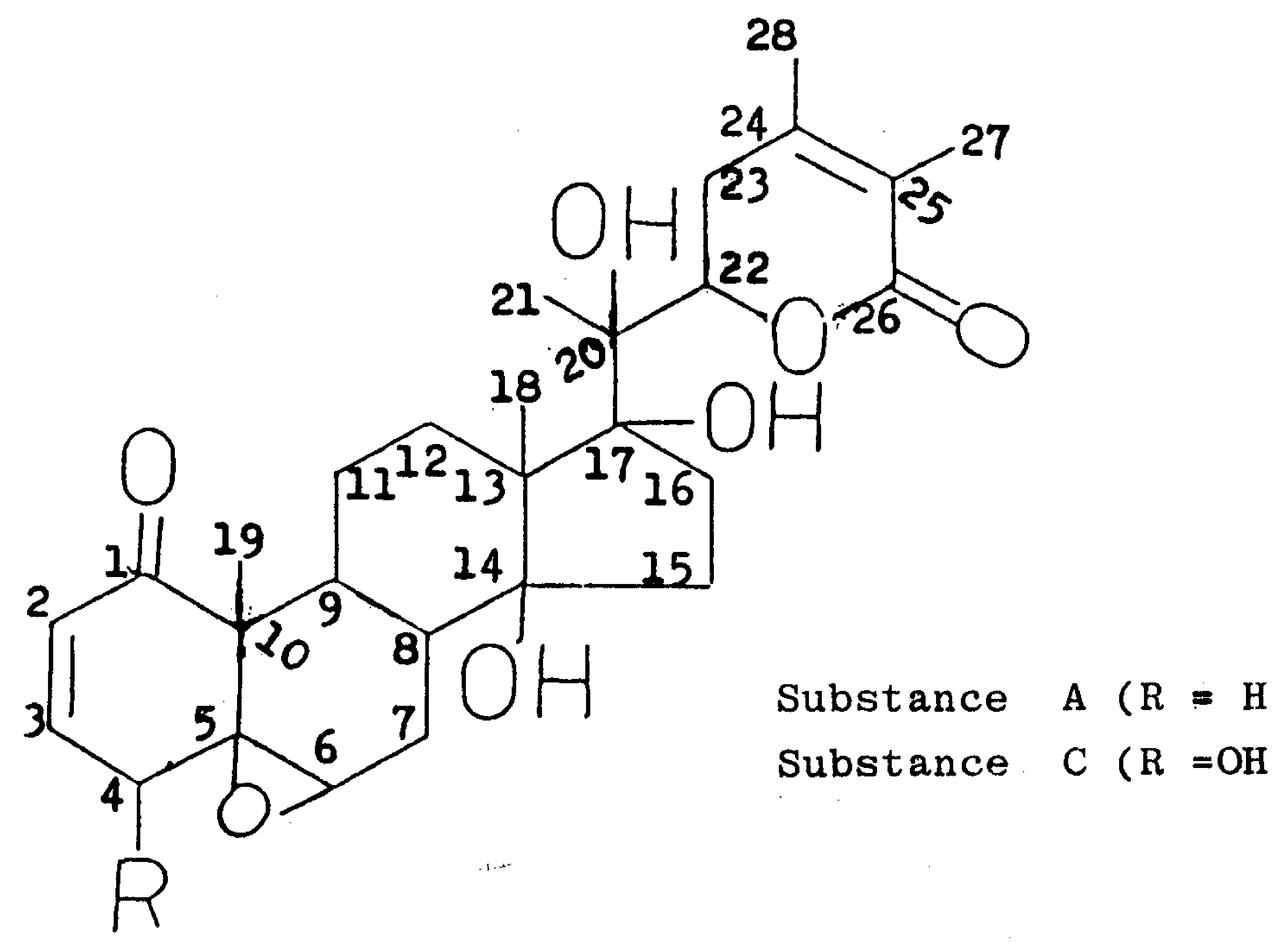

Substance $A$ and substance $C$ show several similarities in the mass spectrum. Both gave $M^{+}-2 x 18$ as the highest $\mathrm{m} / \mathrm{e}$ peak in electron impact mass spectrometer, both with a base peak at m/e 125, and with similar fragments obtained from the side chain at $\mathrm{C}_{17}$ according to reported fragmentation of similar withano Iides $19,20,28$, as shown in Fig. I.

Thus substance $A$ is $14,17,20$-trihydroxy-5B, 6B-epoxy-1-oxo-witha2,24 -dienolide( 1 ). Substance $C$ is $4,14,17,20$-tetra-hydroxy-5B, 6B-epoxy1-oxo-witha-2, 24-dienolide(II), which is isolated for the first time from Withania somnifera or the genus Withania

Kirson et $a^{28}$ reported the isolation of $4 \mathrm{~B}$ hydroxy withanolide E from Physalis peruviana (Solanaceae), which possesses a 17 side chain similar to withanolide E. This compound was reported to have m.p. 197-198 ${ }^{\circ 2}$ which is quite different from that found for substance C (m.p. 277.5 $)$. Thus substance C could be regarded as a configurational isomer of 4B-hydroxy withanolide E. The absolute configuration of the side chain at $\mathrm{C}_{17}$ remains to be determined. 
Withanolides of Withania somnifera $L$. Dunal growing in 539 Egypt

It is worth to mention that substances $A$ and $C$, characterized in this report, appear to correspond to compounds $C$ and B respectively isolated by Khafagy and Ragab ${ }^{25}$, since they show close m.p., similar I.R. data and somewhat related empirical formulae.

From the withanolide pattern of the withanolides isolated from the Egyptian plant, it may be concluded that the Egyptian plant belongs to a new chemotype which is intermediate chemotype II and chemotype III reported in Israel according to Abraham et al 18 
M.M. EL-OZemy et al

440

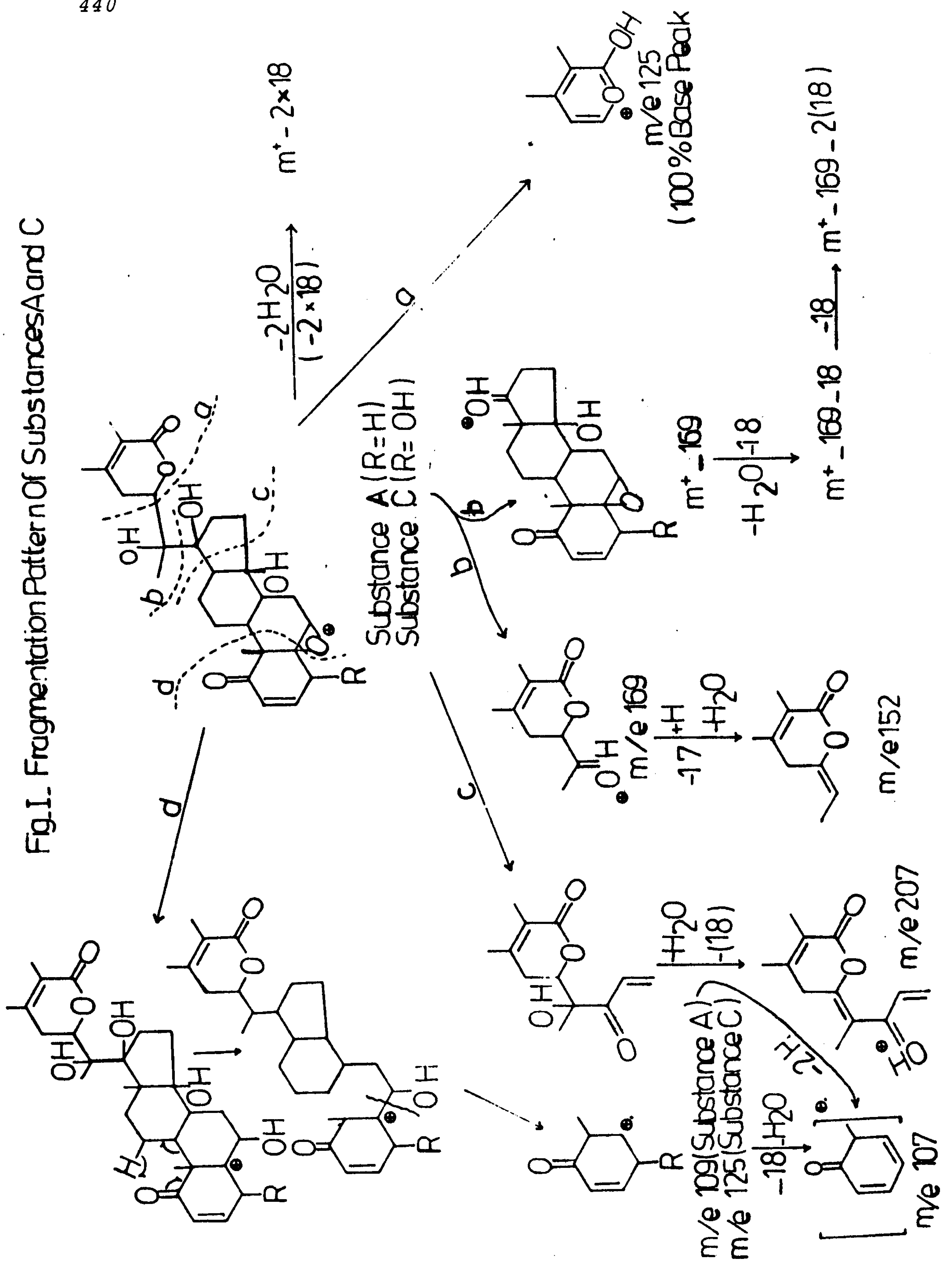


Withanolides of Withania somnifera $L$. Dunal growing in Egypt

\section{REFERENCES}

1) V. Tackholm," Student Flora of Egypt", Cairo University, Faculty of Science, P. 640 (1956).

2) J.M. Watt and M.G. Breyer-Brandwijk, "The Medicinal and Poisonous plants of Southern and Eastern Africa", E.S. Livingstone, Edinburgh-London, P. 1010 (1962).

3) S. Khafagy, A.M. EZ-Moghazy and F. Sandberg, Svensk.Farm. Tidskr., 66, 491 (1962).

4) C.K. Atal and A.E. Schwarting, Eoon. Bot. 15, 256 (1961).

5) A. Rother, C.K. Atal, D. Gold and A.E. Schwarting, J.Chromatog. 5, 178 (1961).

6) K.I. Khanna, A.E. Schwarting and A. Rother and J.M.Bobbitt, Lloydia, 24, 179 (1961).

7) K.I. Khanna, A.E. Schwarting and J.M. Bobbitt, J.Pharm.Sci,, 51, 1194 (1962).

8) A. Rother, J.M. Bobbitt and A.E. Schwarting, Chem.\& Ind., $654(1962)$.

9) J.D. Leary, K.L. Khanna, A.E. Schwarting and J.M. Bobbitt, Lloydia, 26, 44 (1963).

10) A.E. Schwarting, J.M. Bobbitt, A. Rother, C.K.Atal, K.I. Khanna, J.D. Leary and W.G. Watter, LZoydia, 26, 258(1963).

11) D. Lavie and A. Yarden, J. Chem. Soc. (c), 2925(1962).

12) D. Lavie, E. Glotter and Y. Shvo, J. Org. Chem,, 30, 1774 (1965).

13) D. Lavie and E. GLotter and Y. Shvo, J. Chem. Soc.(C),7517 (1965).

14) D. Lavie, S. Greenfield and E. Glotter, ibid(C), $1753(1966)$.

15) D. Lavie, Y. Kashman, E. GLotter and N. Daniezi, ibid (C), 1757 (1966).

16) E. Glotter, R. Waitman and D.Lavie, ibid (C), 1765 (1966).

17) B. Shohat, S. Gitter, A. Abraham and D. Lavie, Cancer Chemother. Reports, s1, 271 (1967).

18) A, I. Kirson, E. GLotter and D. Lavie, Phytochem. ?, 957 (1968).

19) I. Kirson, E.GLotter, A.Abraham and D. Lavie, Tetrahedron, 26, 2209 (1970). 
442

M.M EZ-OZemy \& H.A. Kadry

20) I. Kirson, E. GLotter, D. Lavie and A.Abraham, J.Chem. Soc., (C), 2032 (1971).

21) D. Lavie, I. Kirson, E. Glotter, D. Rabinovich and $Z$. Shakked, J.E.S. Chem. Comm., 877 (1972).

22) E. Glotter, I. Kirson, A. Abraham and D. Lavie, Tetrahedron, 29, 1353 (1973).

23) S.K. Chakraborti, B.K. De and T. Bandyopadhyay, Experientia, 30, 852 (1974).

24) I. Kirson, A. Cohen and A. Abraham, J.C.S. Perkin I, 2136 (1975).

25) S.M. Khafagy and M.S. Ragab, Proceedings of the Tenth Pan Arabian Pharmaceutical Conferense, Part II, Vol. XLVIII, No. 6. P. 609 (1966).

26) M. Kupchan, R.W. Doskotch, P. Bollinger, A.T. Mcphail, G.A. Sim and J.A. Saerz Renauld, J. Amer. Chem. Soc. 87, 5806 (1965).

27) I. Kirson, D. Lavie, S.A. AZbonico and H.R. JuLiani, Tetrahedron, 26, 5062 (1970).

28) I. Kirson, A. Abraham, P.D. Sethi, S. Subramanian, and E. Giotter, Phytochem., 15340 (1976).

29) K.L. Dhar, and M.L. Raina, Phytochem., 12, 476 (1973).

30) G. Adam and M. Hesse, Tetrahedron Letters, 2299 (1971).

31) S.S. Subramanian, P.D. Sethis, E. GLotter, I. Kirson and D. Alvie, Phytochem., 10, 685 (1971).

32) H.G. Menssen and G. Stapel, Planta Medica, 24, 8 (1973). 


$$
\begin{aligned}
& \text { الويثشانوليد ات من نبـات ويثـانها ســومنيفيرا }
\end{aligned}
$$

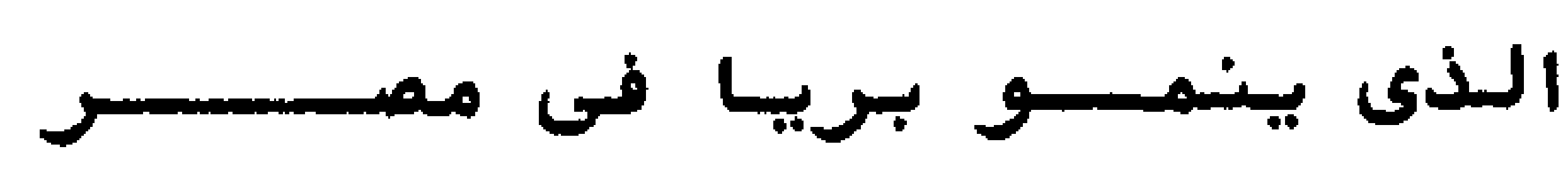

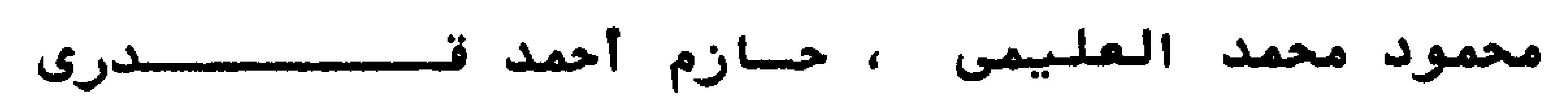
قسم العقاقير - كلية الميدله - جامعة طنطـ قسم العقاقير - كلية الصيدله - جامعة الازهـ

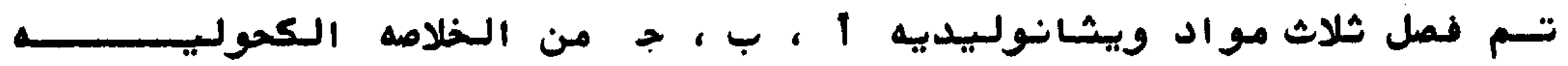

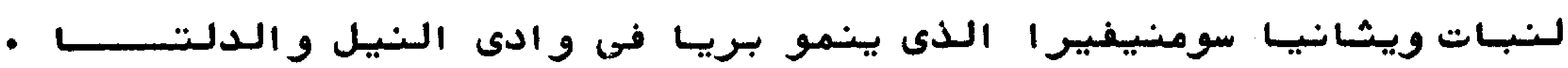

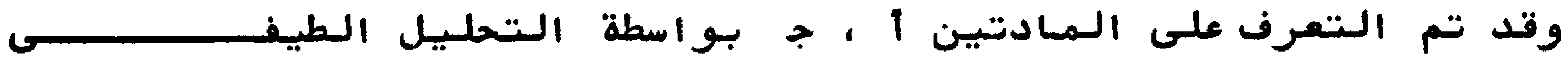

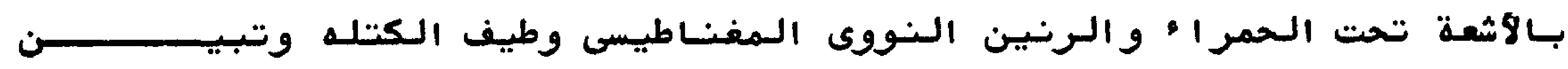

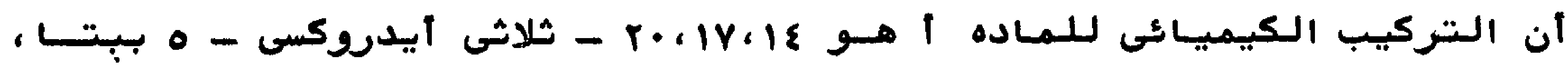

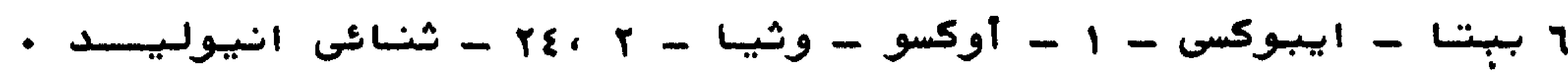

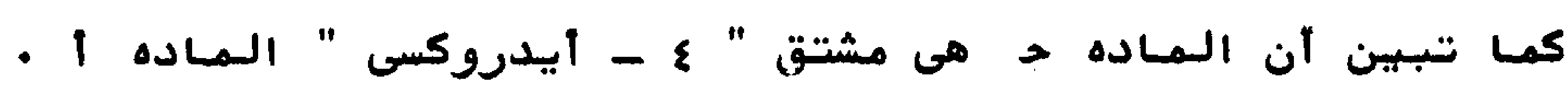

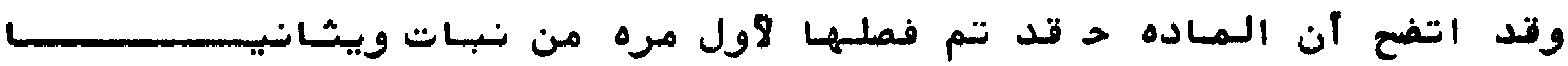
سومنيفير ا او من جنس ويثشنيا عامة أمس المساده الـثالتثه ويثـانـوليد ب فسوف يتم وصف الـتعرف عليهها فى دراســـــــة

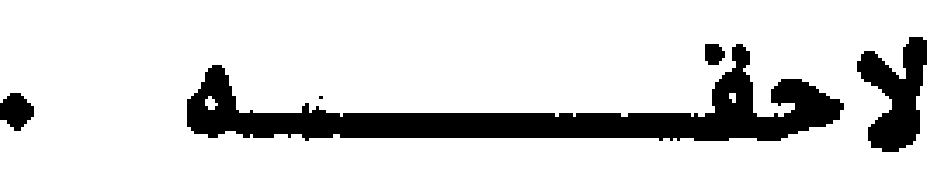

